\title{
Guiding the Use of Grounded Theory in Doctoral Studies - An Example from the Australian Film Industry
}

\author{
Michael Jones and Irit Alony \\ Faculty of Commerce, University of Wollongong, \\ Wollongong, Australia
}

\section{mjones@uow.edu.au iritalony@gmail.com}

\begin{abstract}
Selecting the most appropriate research method is one of the most difficult problems facing a doctoral researcher. Grounded Theory is presented here as a method of choice as it is detailed, rigorous, and systematic, yet it also permits flexibility and freedom.

Grounded Theory offers many benefits to research in Information Systems as it is suitable for the investigation of complex multifaceted phenomena. It is also well equipped to explore socially related issues. Despite existing criticism, it is a rigorous and methodical research approach capable of broadening the perceptions of those in the research community. This paper provides detailed and practical guidelines that illustrate the techniques, utility, and ease of use of grounded theory, especially as these apply to information systems based research.

This paper tracks a Grounded Theory research project undertaken to study the phenomena of collaboration and knowledge sharing in the Australian Film Industry. It uses this to illustrate and emphasize salient points to assist potential users in applying the method. The very practical approach shared in this paper provides a focused critique rendering it a valuable contribution to the discussion of methods of analysis in the IS sphere, particularly grounded theory.
\end{abstract}

Keywords: Research methodology, Grounded Theory, Knowledge Management, Qualitative Methods.

\section{Introduction}

Selecting an appropriate research method is one of the most critical challenges presented to a doctoral researcher. Phillips (1976) likened this element to the Magna Carta of research. The research method must be designed into the research project such that the product of the research is reliable and credible and, importantly for early career researchers, a method that can be applied

Material published as part of this publication, either on-line or in print, is copyrighted by the Informing Science Institute. Permission to make digital or paper copy of part or all of these works for personal or classroom use is granted without fee provided that the copies are not made or distributed for profit or commercial advantage AND that copies 1) bear this notice in full and 2) give the full citation on the first page. It is permissible to abstract these works so long as credit is given. To copy in all other cases or to republish or to post on a server or to redistribute to lists requires specific permission and payment of a fee. Contact Publisher@InformingScience.org to request redistribution permission. easily without decades of refinement and practice.

Among interpretive and qualitative research methods, Grounded Theory offers unique benefits to the doctoral researcher. Grounded Theory "is an inductive, theory discovery methodology that allows the researcher to develop a theoretical account of the general features of a topic while simultaneously grounding the account in empirical ob- 
servations or data" (Martin \& Turner, 1986, p. 141). Grounded Theory provides a detailed, rigorous, and systematic method of analysis, which has the advantage of reserving the need for the researcher to conceive preliminary hypotheses. It therefore provides the researcher with greater freedom to explore the research area and allow issues to emerge (Bryant, 2002; Glaser, 1978, 1992, 1998, 2001). As a consequence, Grounded Theory is useful in providing rigorous insight into areas that are relatively unknown by the researcher.

Despite all these benefits, however, Grounded Theory poses several risks to the doctoral researcher. Foremost among these is the risk that after commencing data collection and analysis, the researcher may not actually uncover substantial or significant theory (also known as a basic social process (Glaser, 1978)). Another risk is the chance that the unorthodox nature of Grounded Theory will alienate the potential recipients from the research findings.

This paper seeks to guide doctoral students who consider using Grounded Theory for their studies. It provides a focused critique of Grounded Theory, which can guide their decision to employ it as a research method. More importantly, this paper details and explains the steps doctoral researchers must undertake in order to reap the benefits Grounded Theory has to offer, by applying it rigorously to the problem examined. To ensure a complete understanding of how to use Grounded Theory, the paper tracks a Grounded Theory research project undertaken to study the phenomena of collaboration and knowledge sharing in the Australian Film Industry.

The Information Systems (IS) phenomenon examined here is knowledge sharing within a project environment. Although knowledge sharing has been recently studied in various contexts, the context of project-based knowledge sharing has been largely overlooked (Ajmal \& Koskinen, 2008). Studies examining inter-firm knowledge sharing (Ko, Kirsch, \& King, 2005), interpersonal knowledge sharing (Gee-Woo, Zmud, \& Sanjeev, 2005; McLure-Wasko \& Faraj, 2005), as well as person-to-repository knowledge sharing (Kankanhalli, Tan, \& Wei, 2005) revealed a myriad of factors that impact knowledge sharing attitudes, intentions, and behavior. However, only a small amount of empirical work has examined the applicability of these factors to the temporary and ad-hoc nature of a project environment (e.g., Boh, 2007).

To explore the underlying issues surrounding knowledge sharing in a project environment, this study selected The Australian Film Industry (AFI). This industry shares many of the characteristics of project teams on one hand (Bechky, 2000; Boh, 2007) and, on the other hand, presents fascinating successful project completions under strict limitations of resources (Alony, Whymark, \& Jones, 2007; Jones, Kriflik, \& Zanko, 2005). Understanding the enablers facilitating effective knowledge sharing in the AFI offers important lessons to other project environments that also rely on effective knowledge sharing for project success (Ajmal \& Koskinen, 2008; Davies \& Brady, 2000). As it appears that no significant attention has been given to studying IS in this environment before, Grounded Theory offers a sensitive and rigorous method for investigation.

As a research method that is liberated from many of the impositions shared by other methods, Grounded Theory can potentially provide a unique insight into the successful process of knowledge sharing in the AFI. This approach was undertaken in order to explore the sharing process and its enablers and supporting factors. The actual study which looks at knowledge sharing in the Australian Film Industry, and its results, will be used here in a capacity limited to practical illustration. For a full discussion of the findings of this research please see Alony et al. (2007).

This paper proceeds as follows. First, the value and benefits Grounded Theory has to offer to IS research is articulated. Then, the criticism Grounded Theory received in this field is discussed. The paper then tracks the steps taken in a study of collaboration and tacit knowledge sharing in the Australian Film Industry (AFI), using Grounded Theory, with the aim of providing the reader an illustrated step-by-step guide for using Grounded Theory in IS. The theoretical underpinning for the practical research steps is provided as well. 


\section{The Value of using Grounded Theory in IS Research}

The benefits offered by Grounded Theory for IS research include the method's capacity to interpret complex phenomena (Charmaz, 2003), its accommodation of social issues (Glaser \& Strauss, 1967), its appropriateness for socially constructed experiences (Charmaz, 2003; Goulding, 1998), it is imperative for emergence (Glaser, 1978; Glaser \& Strauss, 1967), its absence from the constraints of a priori knowledge (Glaser, 1978; Glaser \& Strauss, 1967), and the method's ability to fit with different types of researchers (Martin \& Turner, 1986).

The IS environment is complex and multifaceted (Geri \& Geri, 2011; Skyrius \& Bujauskas, 2010). A full conceptual understanding of it requires the grappling of many interweaved and overlapping issues and themes (Bryant, 2002; Fernández \& Lehmann, 2005; Walsham, 1995). Interpretive research provides to the researcher thick description, which helps to disentangle conceptual relevance (Geertz, 1973). This provides value to those who will benefit from its product by providing meaningful emergent concepts (Charmaz, 2006, 2008; Fernández, 2004). A Grounded Theory study which closely follows the guidelines presented by Glaser and Strauss (1967) will transcend thick description to provide substantive theory (Fernández, Martin, Gregor, Stern, \& Vitale, 2006; Goulding, 2001). This quality of Grounded Theory is further supported by Ellis and Levy (2009) who stated that GT can furnish additional value when literature fails to support the theoretical evolution of phenomena.

Grounded Theory is an important method for studying topics of a social nature. The issues which occupy practitioners within the IS environment are of a socio-technical nature. Fernández and Lehnmanm (2005) argued that for research to maintain most relevance in emerging areas of the socio-technical domain, researchers must adopt a new methodology: "we propose a [new] methodological alternative: grounded theory building research, where the emerging theory helps explain, in conceptual terms, what is going on in the substantive field of research" (p. 2). Other methods may have the effect of forcing preconception through the transfer of inaccurate theoretical assumptions upon the emerging phenomena. Grounded Theory can overcome these problems by providing a lens that does not bias emergence with a priori assumptions and does not thrust forward a selection of preconceived theories from which the researcher must explain the sociotechnical phenomena

Another implication of the social aspect of IS is the constructivist nature of the phenomena. As Walsham $(1995,2006)$ discussed, socially constructed knowledge in IS requires an interpretive approach to inquiry; this renders its interpretation as subjective and value-laden (Galal, 2001). Therefore, data are acquired as composite social constructions of the researcher along with the socially constructed views of those who are being studied (Walsham, 1995). Van Maanen (1979b) divided this composite into first and second order concepts. First order components are the artefacts presented by the subject of the research - these are taken as facts. Second order components are the constructions of the researcher - these lead to the theories the researcher develops to explain the phenomena under study. To put this simply: first order concepts are interpretations, second order concepts are "interpretations of interpretations" (van Maanen, 1979a, p. 541). Grounded Theory provides a means of assembling and sorting first order concepts by looking for patterns and saturation. Grounded Theory also provides a means of drawing out second order concepts through processes of abstraction (Fernández \& Lehmann, 2005). (The methods implicit in these assertions will be discussed in detail in a later section of this paper.)

Walsham (2006) made a salient point in recognizing the importance of fit between the selected method and the researcher. Walsham (2006) explained that by choosing a method the researcher likes, enjoys, and engages with, convincing others of the justification of the method becomes an easier task. It is this convention which drove the selection of Grounded Theory as a method in this study. In the case of this research, Grounded Theory is the method of choice because it en- 
ables an understanding of an area which requires no preformed concepts of knowledge or reality. The ontology and epistemology adopted in this research accepts that knowledge is not static, but is always emerging and transforming, and is interpreted by both observer and participant. Meaning is conveyed through dialogue and action. Within dialogue and action are embedded understanding, experience, and emotion. Only through interaction and discourse can meaning be unlocked and conveyed to the observer. From this perspective, Grounded Theory provides a method which enables a researcher to adduce true meaning and understanding.

As a research method, Grounded Theory has not gone without criticism. The following section explains, discusses and addresses the most widespread of these criticisms.

\section{Criticisms of Grounded Theory}

As with most research methods, Grounded Theory does not exist without its critics. The most common criticism in the field of IS rests with a claim that while the method uses interpretivist and constructionist tools, it stems from positivism/objectivism. It therefore suffers from internal misalignment (Bryant, 2002). The following section addresses this criticism in detail. Other points of criticism include naive inductionism (Bryant, 2002; Goulding, 2001), limitations on a priori knowledge (Bryant, 2002; Charmaz, 2006; Goulding, 2001), phenomenalism (Goulding, 2001), the paradox of 'theory' (Bryant, 2002; Charmaz, 2006), and limited theoretical generalisation (Burawoy, 1991; Nasirin, Birks, \& Jones, 2003; Charmaz, 2006). Addressing these criticisms is outside the scope of this paper.

Various researchers have differing ideas on the philosophical location of Grounded Theory. Some view it as a positivist/objectivist method, due to the language used by Glaser and Strauss (1967) in their book titled 'The Discovery of Grounded Theory'. Terms like 'emergence' and 'discovery' suggest an objective realist perspective, accepting only one 'true' reality (Locke, 2001). The main reason for this assumption probably lies in the fact that Glaser and Strauss established a strong argument for a structured method of qualitative analysis (Charmaz, 1990, p. 253):

Glaser and Strauss's (1967) work was revolutionary because it challenged (a) arbitrary divisions between theory and research, (b) views of qualitative research as primarily a precursor to more "rigorous" quantitative methods, (c) claims that the quest for rigor made qualitative research illegitimate, (d) beliefs that qualitative methods are impressionistic and unsystematic, (e) separation of data collection and analysis, and (f) assumptions that qualitative research could produce only descriptive case studies rather than theory development.

Denzin and Lincoln (2000) introduced Grounded Theory as an institutional icon in the modernist paradigm. This finding may have been heavily influenced by the date of publication of the original monograph in 1967. That year lay well within Denzin and Lincoln's (2000) espoused second movement. It may also have been informed by Glaser's strong positivist background, a view supported by Charmaz (2003).

In contrast to this view, Glaser and Strauss (1967) argued for a movement away from a positivistic association (Hutchinson, 1988; Suddaby, 2006). They proffered their work as a solution to some of the concerns they saw at the time: "[Grounded Theory] came forward ... in response to the extreme violations brought to data by quantitative, preconceived, positivistic research using forcing conjectured theory" (Glaser, 2001, p. 6). Grounded Theory was developed to avoid highly abstract sociology. It was a big part in the change of qualitative analysis during the 1960s and 1970s (Goulding, 1998, p. 6). Through developing theory by 'grounding' it in data, Glaser and Strauss were able to bridge the void between theoretically 'uninformed' empirical research and empirically 'uninformed' theory (Charmaz, 1983). 
Goulding (1998) and Locke (2001) suggested that Grounded Theory lies closer to an interpretive paradigm, citing its association with American pragmatism and the symbolic interactionist school of sociology. Glaser supports this view citing the influence of Strauss with his strong background in symbolic interactionism gained at the Chicago School of Symbolic Interactionism and claiming: "through Anselm [Strauss], I started learning the social construction of realities by symbolic interaction making meanings through self-indications to self and others. I learned that man was a meaning making animal" (Glaser, 1998, p. 32).

Glaser (2005) tended to be ambivalent about the position of Grounded Theory and stated that Grounded Theory is intended as an alternative to all paradigms: "[Grounded Theory] is not an either/or method. It is simply an alternative to positivistic, social constructionist and interpretive qualitative data methods" (Glaser, 2001, p. 6). Glaser (2001) emphasizes that a method's selection is to be guided by the needs of the research, rather than by any one paradigmic bias: "My bias is clear, but this does not mean I rubber stamp 'ok' or indite any method. The difference in perspectives will just help any one researcher decide what method to use that suits his/her needs within the research context and its goals for research" (Glaser, 2001, p. 2).

\section{Two Grounded Theory Schools}

Grounded Theory was initially developed by two researchers - Barney Glaser and Anselm Strauss (1967). However, early in its development the two researchers separated and a bifurcation of the theory enveloped (Glaser, 1992; Strauss \& Corbin, 1990). We now have two fundamental schools for Grounded Theory: the Glaserian School and the Straussian School (Stern, 1994). The differences between these are many, and in cases somewhat minor. The major differences, however, can have an important impact in the direction and execution of the primary research. For instance, Glaser takes the stance that researchers should have an empty mind, while Strauss permits a general idea of the area under study. Glaser leads with the principle that theory should emerge, while Strauss uses structured questions to lead a more forced emergence of theory. These differences and others are detailed in Table 1. This discussion has been borrowed from Onions (2006).

Table 1: Comparisons of the two schools of Grounded Theory

\begin{tabular}{|l|l|}
\hline \multicolumn{1}{|c|}{ 'GLASERIAN' } & \multicolumn{1}{|c|}{ 'STRAUSSIAN' } \\
\hline $\begin{array}{l}\text { Beginning with general wonderment (an empty } \\
\text { mind) }\end{array}$ & Having a general idea of where to begin \\
\hline Emerging theory, with neutral questions & Forcing the theory, with structured questions \\
\hline Development of a conceptual theory & $\begin{array}{l}\text { Conceptual description (description of situa- } \\
\text { tions) }\end{array}$ \\
\hline $\begin{array}{l}\text { Theoretical sensitivity (the ability to perceive } \\
\text { variables and relationships) comes from im- } \\
\text { mersion in the data }\end{array}$ & $\begin{array}{l}\text { Theoretical sensitivity comes from methods } \\
\text { and Tools }\end{array}$ \\
\hline The theory is grounded in the data & The theory is interpreted by an observer \\
\hline $\begin{array}{l}\text { The credibility of the theory, or verification, is } \\
\text { derived from its grounding in the data }\end{array}$ & $\begin{array}{l}\text { The credibility of the theory comes from the } \\
\text { rigour of the method }\end{array}$ \\
\hline A basic social process should be identified & Basic social processes need not be identified \\
\hline $\begin{array}{l}\text { The researcher is passive, exhibiting disci- } \\
\text { plined restraint }\end{array}$ & The researcher is active \\
\hline Data reveals the theory & Data is structured to reveal the theory \\
\hline
\end{tabular}




\begin{tabular}{|l|l|}
\hline \multicolumn{1}{|c|}{ 'GLASERIAN' } & \multicolumn{1}{c|}{ 'STRAUSSIAN' } \\
\hline $\begin{array}{l}\text { Coding is less rigorous, a constant comparison } \\
\text { of incident to incident, with neutral questions } \\
\text { and categories and properties evolving. Take } \\
\text { care not to 'over-conceptualise', identify key } \\
\text { points }\end{array}$ & $\begin{array}{l}\text { Coding is more rigorous and defined by tech- } \\
\text { nique. The nature of making comparisons var- } \\
\text { ies with the coding technique. Labels are care- } \\
\text { fully crafted at the time. Codes are derived } \\
\text { from 'micro-analysis which consists of analysis } \\
\text { data word-by-word' }\end{array}$ \\
\hline $\begin{array}{l}\text { Two coding phases or types, simple (fracture } \\
\text { the data then conceptually group it) and sub- } \\
\text { stantive (open or selective, to produce catego- } \\
\text { ries and properties) }\end{array}$ & $\begin{array}{l}\text { Three types of coding, open (identifying, nam- } \\
\text { ing, categorising and describing phenomena), } \\
\text { axial (the process of relating codes to each oth- } \\
\text { er) and selective (choosing a core category and } \\
\text { relating other categories to that) }\end{array}$ \\
\hline Regarded by some as the only 'true' GTM & $\begin{array}{l}\text { Regarded by some as a form of qualitative data } \\
\text { analysis (QDA) }\end{array}$ \\
\hline
\end{tabular}

The research described in this paper adopts the former methodology, that of Glaser. This method has been selected in favor of the Straussian School primarily as a result of the Glaserian method maintaining a focus on its more pure origins and due to its more emergent nature over the more prescriptive edicts of the Straussian style (Stern, 1994).

\section{Overview of the Research Project - Knowledge Sharing in the Australian Film Industry}

The study was part of a larger investigation of the Australian Film Industry (AFI), focusing on collaboration, knowledge transfer, and knowledge sharing in a project environment. Being complex, multi faceted, and socially driven, this activity of knowledge exchange is an appropriate subject to study using Grounded Theory (Orlikowski, 2002). The research focuses on the information flow between participants, looking for events of knowledge sharing and factors enabling it. The findings elucidated three issues:

1. The nature of knowledge sharing in the AFI: tacit or explicit knowledge

2. The difference between information flow and knowledge sharing

3. The different factors which enable and inhibit this sharing of knowledge

Knowledge sharing was selected as a research topic as it has been found to improve organisational performance (Haas \& Hansen, 2007; Lesser \& Storck, 2001), to promote competitive advantage (Argote \& Ingram, 2000), to enhance organisational learning (Argote, 1999), to increase innovation (Powell, Koput, \& Smith-Doerr, 1996), and to support organisational survival and sustainability (Baum \& Ingram, 1998). However, not all organizations can easily facilitate knowledge sharing. Project-based organizations find this facilitation challenging (Cooper, Lyneis, \& Bryant, 2002) due to the temporary, transient, and customized nature of projects (Boh, 2007).

Project-based organizations rely on temporary and ad-hoc structures for completion of tasks. From a task perspective, each customized project tends to differ from others in several critical aspects. This makes it difficult to transfer lessons learned across projects (Meyerson, Weick, \& Kramer, 1996). From a relationship perspective, team members tend to vary from one project to another. This renders the conduits of knowledge transfer (i.e., relationships) transient and potentially less effective (Hobday, 2000). Despite these limitations, project-based organizations are particularly useful for tasks that require creativity, innovation, and diverse perspectives (Boh, 2007; Davies \& Brady, 2000; Hobday, 2000). 
The ultimate project-based environment is the film industry, where project teams form around each movie based on specific requirements of expertise (Bechky, 2000; Daskalaki \& Blair, 2002; Mintzberg \& McHugh, 1985). These members may or may not have worked together in the past, therefore suggesting various degrees of relationship strengths. Film production teams draw together individuals with different types of expertise, and thus knowledge specific to individuals, which is not held by others, is common (Cattani \& Ferriani, 2008). Similar to most industry projects, Australian film production teams are under pressure of time and resources, as project deliverables must meet deadlines within budget constraints (Jones \& Alony, 2007). The success of film projects is heavily reliant on collaborative processes, which include knowledge transfer (Cattani \& Ferriani, 2008). The AFI work environment is challenging and stressful. This demands swift and accurate results, without tolerance for ambiguity, inaccuracy, or failure (DeFillippi \& Arthur, 1998; Jones \& Alony, 2007). The fact that many film projects are completed successfully in the AFI suggests that knowledge transfer is effective in this industry. Factors that support knowledge sharing and enable its success in such harsh conditions can therefore serve as powerful lessons for other project environments.

To understand what enables and supports knowledge sharing in project teams, and due to a lack of prior research into this context, Grounded Theory was employed. Since knowledge has been described as an "ongoing social accomplishment, constituted and reconstituted as actors engage the world in practice" (Orlikowski, 2002, p. 249), investigating the process of its sharing with the holistic view provided by Grounded Theory enables the capturing of the influence of many situational variables involved. This approach for studying knowledge work has been argued for by others as well (Bechky, 2006). Knowledge sharing and collaboration within the AFI has not been previously studied; it therefore justified an exploratory approach.

The results of this study found five groups of factors impacting on the success of the process of knowledge sharing during collaboration: individual, relationship, network, organization, and knowledge. In addition, the results showed that individual motivation has the potential to override the influence of all other factors and to support a successful knowledge sharing process. The full results of this project can be found in Alony et al. (2007). The aim of this paper is to provide the reader with an understanding of how to use Grounded Theory for such research. The following section details the methodological process undertaken in this study.

\section{Using the Grounded Theory Method}

This section integrates our Grounded Theory design by interlacing theoretical guidelines with practical insights from the study described above. For ease of communication this discussion necessitates a mix of first and third person, where first person represents the practical side of the example (also underlined for clarity) and third person will represent theoretical doctrine. An advantage of the first person here is that it provides a more subjective view of the research process, and since subjectivity is an inherent component of qualitative research, this strategy is perhaps appropriate.

The process of Grounded Theory encompasses an acknowledgment of the researchers' bias, the selection of a data collection site, the data collection process, the process of coding and analysis, and the compilation of results. Coding and analysis includes three stages: open coding, selective coding, and theoretical coding. Open coding employs constant comparison and memoing and results in themes, sub-categories, and core categories. These results guide the subsequent sampling of participants through theoretical sampling. The next stage of coding - selective coding - also employs constant comparison and memoing. This stage results in dense, saturated core categories. The core categories are then sorted, written, theorized, and cross-referenced with literature, during theoretical coding. The results of this last stage of coding are a basic social process and a theoretical model. This is the final product of Grounded Theory research. This research process is 
summarized in Figure 1. This section explains each part of the process, and illustrates how it was undertaken in the study of the AFI.

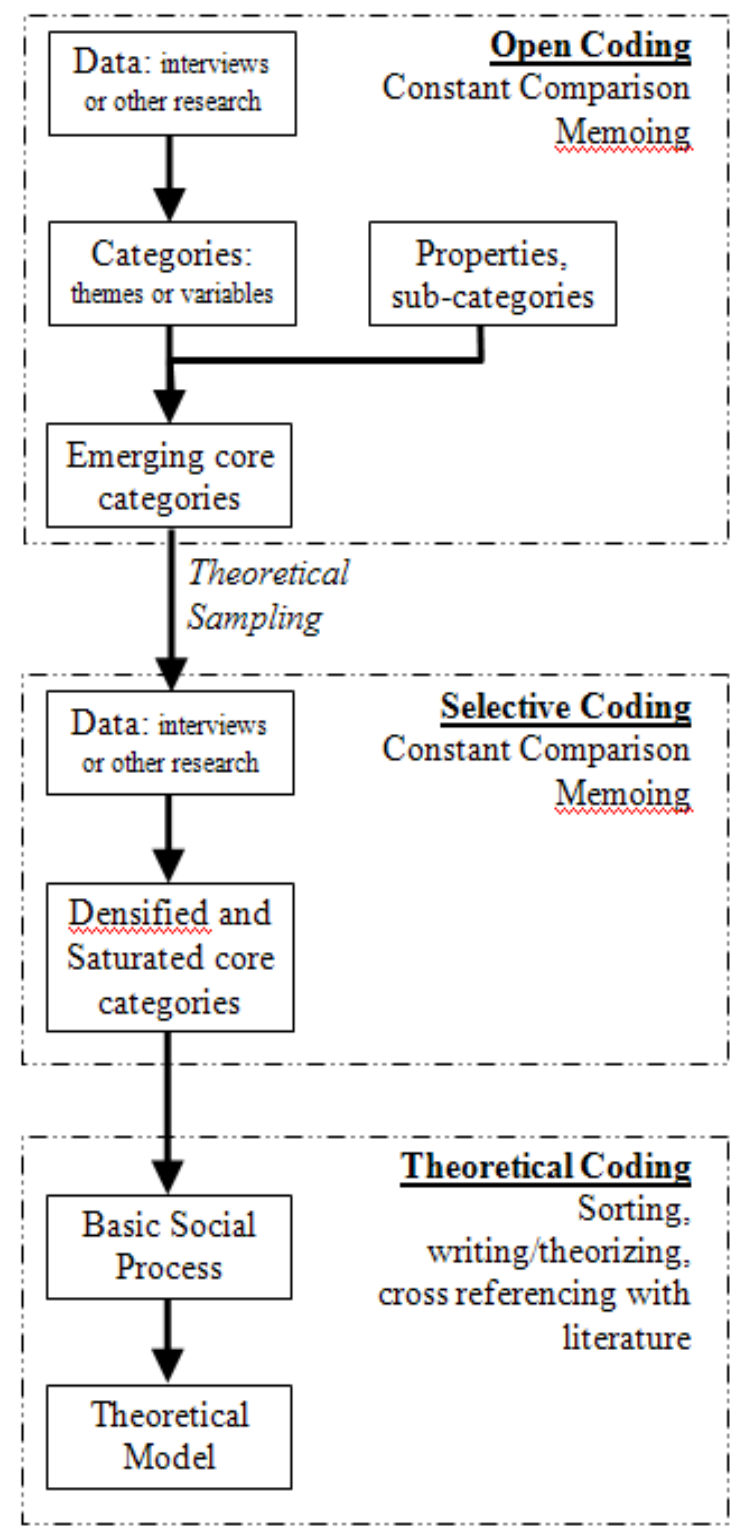

Figure 1. The Process of Grounded Theory

\section{Acknowledge Biases}

An initial step in qualitative research, in particular Grounded Theory, is for the researcher to disclose influences which may bias the study. By acknowledging researcher biases, the work gains a degree of scientific hardiness. In addition, Glaser and Strauss (1967) recommended researchers enter the field without preconceived or a priori ideas of the subject area, of what may be discovered, or where it may lead. However, as many writers have testified (Charmaz, 2003; Hettinga, 1998), it is very difficult, if not impossible, to totally divorce one's self from the accumulations of knowledge and experience which temper understanding, observation, and interpretation. Researchers must therefore disclose information which may affect understanding. Disclosure will do two things. Firstly, it will inform the reader of areas where objectivity may be at risk of not being 
absolute. More importantly though, it will communicate that we, as researchers, are aware of these potential biases and have endeavored to account for them.

Not unlike other interpretive methods, researchers must be aware of two potential biases: double hermeneutic and the Hawthorne effect. This caveat is not limited to the use of Grounded Theory. Interpretive researchers must acknowledge this role and its potential for affecting the results (Walsham, 1995). The first bias, double hermeneutic, as termed by Giddens (1984), suggests the subject of the research is influenced by the research and by the researcher. Given time, the subject will eventually learn from the research and modify his or her behaviour. The other bias is known as 'the Hawthorne effect' (Landsberger, 1958). Landsberger studied the famous Hawthorne experiments to try to understand the extraordinary outcomes of the research. In doing so, he found that people have a tendency to do things to please the researcher, and this can result in artificial results. Researchers must bear these influences in mind when preparing research, collecting data, and writing up and reporting results.

We entered the study with little prior knowledge of the AFI, knowing nothing about film production. In order to gain some initial knowledge of the film industry, of the jargon used, and to gain some of the requisites for the development of theoretical sensitivity (Glaser, 1978) we undertook an initial pilot study. Following this we interviewed several film producers at a film conference. These activities served to provide some basic general knowledge. Glaser and Strauss (1967) stressed that developing theoretical sensitivity is essential for the proper emergence of Grounded Theory.

Following the prescribed methods of Glaserian Grounded Theory (Glaser 1978, 1992, 1998, 2001, 2005; Glaser \& Kaplan, 1996; Glaser \& Strauss, 1967), empirical data were collected from film workers. Initial inquiries were directed toward management practices in general. However, as the basic social process began to emerge, the research became more and more focused toward the actual social problem as related by the participants. As Glaser and Holton (2004) stated:

GT provides an honest approach to the data that lets the natural organization of substantive life emerge. The GT researcher listens to participants venting issues rather than encouraging them to talk about a subject of little interest. The mandate is to remain open to what is actually happening and not to start filtering data through pre-conceived hypotheses and biases to listen and observe and thereby discover the main concern of the participants in the field and how they resolve this concern. (p. 11)

\section{Begin Data Collection}

A Grounded Theory study begins with a general opening of a subject area. As stated by Dey $(1999$, p. 3), the researcher will usually start with a "general subject or problem conceived only in terms of a general disciplinary perspective." From this initial opening, the study becomes continually focussed towards an area of social concern. Once a data site has been selected, collection of data begins, this is usually in the form of open-ended interviewing and transcription, but can include other forms of data acquisition such as documents and literature. Glaser comments that "all is data" meaning just that: "exactly what is going on in the research scene is the data, whatever the source, whether interview, observations, documents. It is not just what is being, how it is being and the conditions of it being told, but all the data surrounding what is being told" (Glaser, 2001, p. 145).

The selection of our initial participants was based on introductions from our University. Introductions were necessary as these people were generally high profile and were also accustomed to working unusual hours. It was both courteous and convenient to secure an introduction before contacting each of the participants. Following the guidelines of Theoretical Sampling (Glaser, 1978), each participant was asked to recommend a number of people who would potentially sat- 
isfy our expected needs for theoretical sampling and densification. After analysis we determined which of these potential participants would be most suited to the research by examining their biographies and filmographies. Through this examination of their history and experience we could determine whether they would be suitable according to what we thought they could add to the study in relation to the data we were obtaining. When we determined which of the potential contacts were most useful we would ask the person we had interviewed if they could contact this person and introduce us. This did not work in all cases - due to various reasons, usually because the person was busy working; in these cases we would ask for an introduction to our next preferred participant.

The first two interviews were held on the same day with two film producers in two separate locations. These initial interviews went from 90 to 120 minutes each, both yielding rich information. The data were of such high quality that nearly all of it was used in the study. After these first two interviews, subsequent interviews became progressively shorter as the study progressed, with the final interviews running just short of one hour each. Glaser and Strauss (1967) explain that it is customary for interviews to run this way.

The first two producers were each asked the same set of questions. These questions were openended, allowing for significant prompting and focusing. During the interviews a digital voice recording was made, along with notes, which enabled us to recall certain expressions and body language that would convey information pertinent to the participants' intended meaning. For example, in response to a question on the importance of communication, Sara responded by saying:

I think communication is a really, really important skill. I'm not going to claim that most producers don't have that, but I think being able to talk to people on a human level is vital and to listen to what people say. That's one of the main skills of producers. Listening to what everybody has to say. (Interview with Sara, a Line-Producer)

During this part of our conversation she became very animated and raised her voice a little. We interpreted this to mean that this aspect of her job was very important to her. Similar notations and allowances were made through all of the interviews to enable further interpretation of the information that was conveyed during the meeting. This is similar to what Glaser terms as listening "with a big ear", meaning to use all avenues of interpretation (Glaser, 2001, p. 175).

\section{Coding}

After the empirical data have been collected the researcher begins the process of coding - categorizing the data to reflect the various issues represented. The Glaserian Grounded Theory method uses three levels of coding - open coding, selective coding, and theoretical coding. The coding stages are consecutive and sequential and not iterative. The product of each stage guides the following stage.

\section{Open coding}

Initially, open coding is employed. At this stage, the raw data (for example, transcripts) are initially examined and are coded through a process which fractures the interview into discrete threads of datum. These data are collated and accrue to form categories of similar phenomena. The process of open coding examines the data without limitations in its scope and without the application of any filters, thus all data are accepted and none are excluded. This allows the researcher to look for patterns that may lead to social processes which may be of eventual interest. As the categories begin to fill, those that are most dense become known as core categories (Glaser, 2001). Through this process of densification, core categories build to become the core focus of theoretical articulation through to the development of a basic social process (Glaser, 1978, p. 93). 
Almost immediately upon completion, the two interviews were transcribed and coding began. It is important to begin this parallel task of collection and coding in a timely and synchronous manner to ensure a structured discovery of data which more easily illuminates emerging themes and potential areas of enquiry (Backman \& Kyngäs, 1999). Data were coded following the prescribed process of open coding. This involved systematically reading and considering every comment made by each participant in an effort to find similarities between concepts. Then, these concepts were coded according to their meaning and relevance to the study. As this was our first set of interviews, we were interested in all the respondents had to say, and as a consequence we coded the entire transcript (Glaser, 1978). At this stage we were unable to identify the data which were not relevant to the emerging concepts.

\section{Constant comparison}

Open coding utilizes a process of constant comparison (Glaser \& Strauss, 1967). Constant comparison is a simultaneous and concurrent process of coding and analysis (Partington, 2000). As categories start to accumulate and gain depth, constant comparison compels the researcher to begin to reflect on the data and to commence conceptualization, usually using 'memos' to record the researchers' reflections and annotations of the data. This eventually leads to hypothesis and theory: "The purpose of the constant comparative method of joint coding and analysis is to generate theory more systematically ... by using explicit coding and analytic procedures" (Glaser \& Strauss, 1967, p. 102). "The constant comparative method is designed to aid the analyst ... in generating a theory that is integrated, consistent, plausible, close to the data" (Glaser \& Strauss, 1967, p. 103). Figure 2 illustrates the process of constant comparison. The process does not, however, yield tested theory. It produces a substantive theory which derives from a set of plausibly induced (but not scientifically tested) categories, properties, and hypotheses which regard real social problems (Glaser \& Strauss, 1967, p. 104). Validity arises through data saturation - when no new concepts emerge.

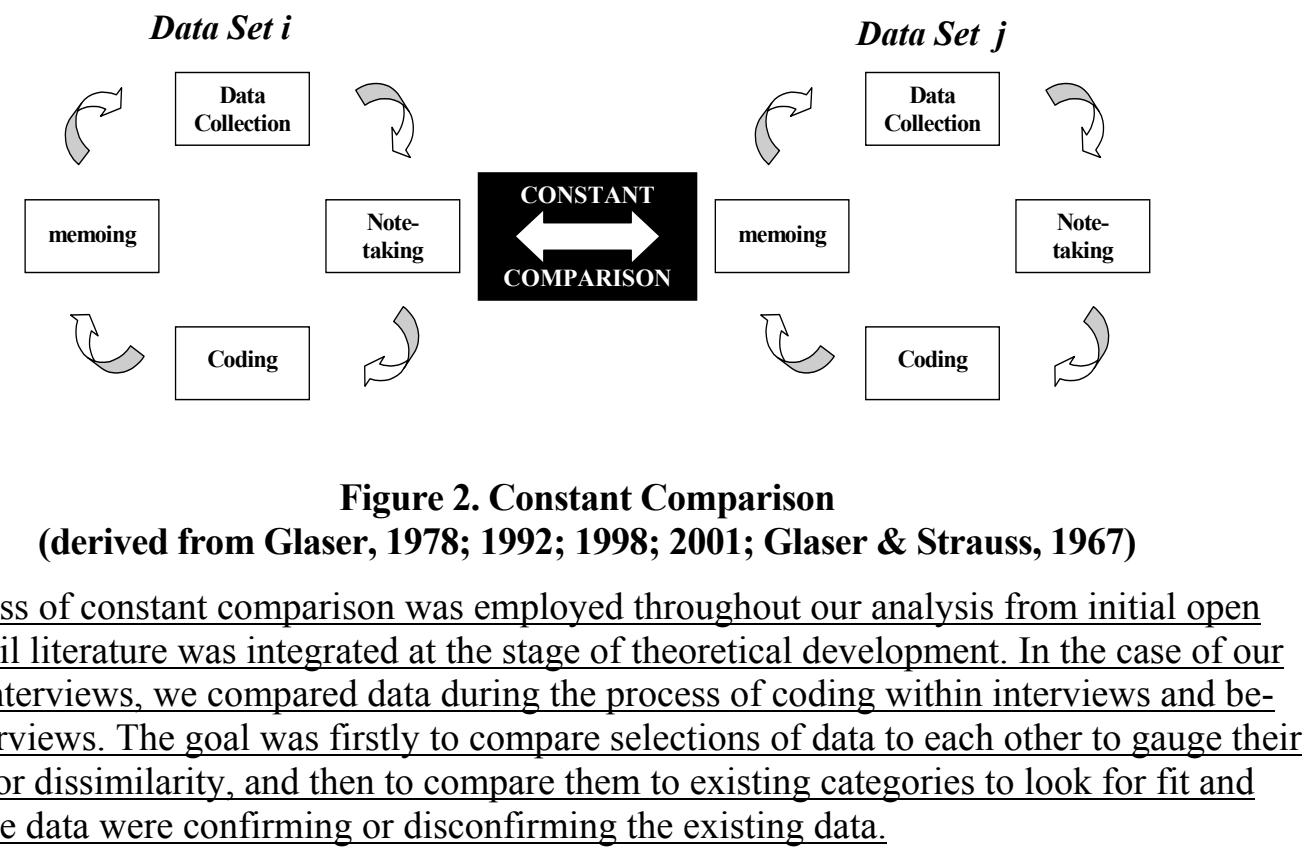




\section{Memoing}

Glaser refers to memoing as "the core stage in the process of generating theory, the bedrock of theory generation" (Glaser, 1978, p. 83). Memos have four basic goals: they should develop ideas and codes, these ideas should develop freely, should be stored centrally, and should be sortable (Glaser, 1978, p. 83).

When recording memos, researchers should reflect on the data but should not limit their reflection to just the data. Everything is an important reflection. The rule is to write down everything - no matter how bizarre or nonsensical - and to interrogate one's feelings and thoughts constantly. Martin and Turner describe this style of writing as a free-flowing style which is free from any self-editing (1986, p.151).

As data began to accumulate into categories, we needed to reflect on what was emerging. This process of reflection was greatly enhanced through the use of memos. As our categories filled through constant comparison and constant reflection, our memos started to become rich and reflective. Memos are an important part of the Grounded Theory process. In our case they enabled us to become reflective very early in the research, while there was still time to fine tune data collection.

In our case, we questioned what the participants were telling us. We commented on inconsistencies and discrepancies and noted when they were more, or less, passionate in their narratives. For example, the first producer we spoke to was talking about his most recent production (quite a well known and controversial film), and when he spoke about the difficulties he became very passionate about 'how' and 'what' the crew did to overcome these difficulties and how he was in awe of their energy, creativity, and drive. This higher level of passion in his narration was noted and included in all associated codes and categories. This later became a very important notation which was observed in other producers when they regarded similar situations.

Constant comparison continues until core categories emerge from the data, and no significant new phenomena are reported.

\section{Theoretical sampling}

As data are being coded, compared, and accumulated to form categories and core categories, an on-going process of sampling takes place, known as theoretical sampling. Theoretical sampling regards the process of data collection, where new targets for data collection are directed by the results collected from the preceding sample. The aim is to systematically select new participants or data which will guide the researcher to select data samples which are most salient for the research being undertaken. Theoretical sampling works by selecting subsequent participants based on the information which emerges from the data already coded (Sarantakos, 2005, p.166). This process provides a means of ensuring that new data contribute to theory development and that they work with the concepts already compiled through a measure of fit and relevance (Glaser, 1978). New data are confirmed and disconfirmed to ensure the emerging theory develops rigor and parsimony.

There are two main steps involved with theoretical sampling. In the first step, the researcher targets participants who share minimal differences with regard to the subject under examination. After data from this step have passed the scrutiny of constant comparison, the sampling moves to the second step. In this step, an enlargement of the sample commences until differences between participants are maximized. By initially minimizing differences, the researcher is able to quickly develop categories and determine their properties. By maximizing differences the researcher can ensure categories have been fully developed and that data saturation is actually occurring (Glaser, 1978). 
Saturation was an indication for us to begin to widen the sample to other areas of data collection, for example, a move from producers to production managers (Glaser \& Strauss, 1967, p. 61). New sample groups were desirable at this stage as large differences in groups would "maximize the varieties of data bearing on a category, and thereby develop as many diverse properties of the category as possible" (Glaser \& Strauss, 1967, p.62). The analysis therefore suggested that we should start to explore other areas for the next level of data collection. The interviews we were to undertake in the next round were with film workers who were lower down in the film management hierarchy.

\section{Selective coding}

The second stage, selective coding, is reached when core categories become apparent. A core category is a category that has developed through densification and that explains most of the variation which represents the participants' major concern. The core category should be an issue upon which the basic social process is centered. It should relate meaningfully and easily to other categories. It should have clear and grabbing qualities (Glaser, 1978; Glaser \& Holton, 2004).

Selective coding allows the researcher to filter and code data which are deemed to be more relevant to the emerging concepts. Therefore, only the most pertinent passages of a transcript are used and coded. To facilitate this, interview questions are continuously reformulated to encompass the new and more focused direction of the research.

In our case, the core category had been abstracted from various sub-categories to form one core. All of the participants who had been interviewed to this point had expressed concerns which related to this core concept and the concepts which were grouped into this category. It is this degree of saturation - in both breadth and depth - which led to its selection. An issue which was repeatedly mentioned, emphasized, and related to by the participants was that of collaboration. Collaboration was portrayed as being crucial for the success of a project, in this case, film production. Emerging sub-categories included the different factors, situations, and conditions impacting on the success and failure of collaboration.

Through coding we were able to accumulate data into categories which were most relevant to the study. Where data accumulated most densely we started to focus in on a core category. Interview questions became more focused and the resulting interviews shorter, containing richer data. These interviews were also transcribed and coded. However this time, as the direction of investigation was known, we used selective coding.

Our use of selective coding meant that during coding we only picked out relevant data from the transcripts and only added these to the core category where they added value. As a result, many of the categories building the core category became saturated (the additional data collected yielded no new insights or phenomena). It was now safe for us to assume that the core category was empirically mature (Glaser \& Strauss, 1967). To ensure that this was the case and to ensure that the categories were wide enough to encompass all relevant phenomena, we acquired second source data from film literature and coded these data into the emerging process to look for concepts that would fill gaps in the model.

\section{Theoretical coding}

The final stage of coding is known as theoretical coding. Theoretical coding occurs when core categories have become saturated. Saturation is both a peculiarity and strength of Grounded Theory. Unlike other methods of qualitative analysis which acquire rigor through multiple levels of confirmation or triangulation (Mertens, 1998), Grounded Theory builds an analytical case by constantly seeking new categories of evidence. Eventually, after a period of data collection, a point is reached where no new data result from additional data collection. This is the point of saturation: 
"One keeps on collecting data until one receives only already known statements" (Seldén, 2005, p. 124).

Theoretical coding examines these saturated categories and provides the researcher with analytical criteria for the development of conceptual relationships between categories and their relevance to the literature (Glaser, 1992; 2005; Glaser \& Kaplan 1996). As the coding procedure before this phase worked to fracture the data and cluster them according to abstract similarity, theoretical coding, along with sorting, knits the fractured pieces back together again to conceptualize causal relationships between the hypotheses derived through open and selective coding: "Theoretical codes give integrative scope, broad pictures and a new perspective. They help the analyst maintain the conceptual level in writing about concepts and their interrelations" (Glaser \& Holton, 2004, p.9). A meaningful schema of interpretation of the causal relationships is produced, linking the conceptual outcomes of the analysis. Glaser $(1978,1998,2005)$ identifies 50 families of theoretical codes to identify what he calls "latent patterns" (Glaser, 2005, p.5).

To assist with this process of conceptual development we used theoretical coding to fully explore and analyze all new and existing data (Glaser, 1978, 2005). These theoretical codes assisted in the recognition of patterns and in the process of theorizing what was actually happening during the process of collaboration and knowledge exchange. The various factors impacting on knowledge exchange were consolidated into five groups, as shown in Figure 3: individual, relationship, network, organization, and knowledge. The influence of each factor on the success of knowledge exchange process was identified. Our use of theoretical coding worked to ensure consistency and objectivity in our process of analysis (Glaser, 1978). Glaser states that the use of theoretical codes is not necessary, but "a GT is best when they are used ... a GT will appear more plausible, more relevant and more enhanced when integrated and modeled by an emergent TC" (Glaser, 2005, p.14).

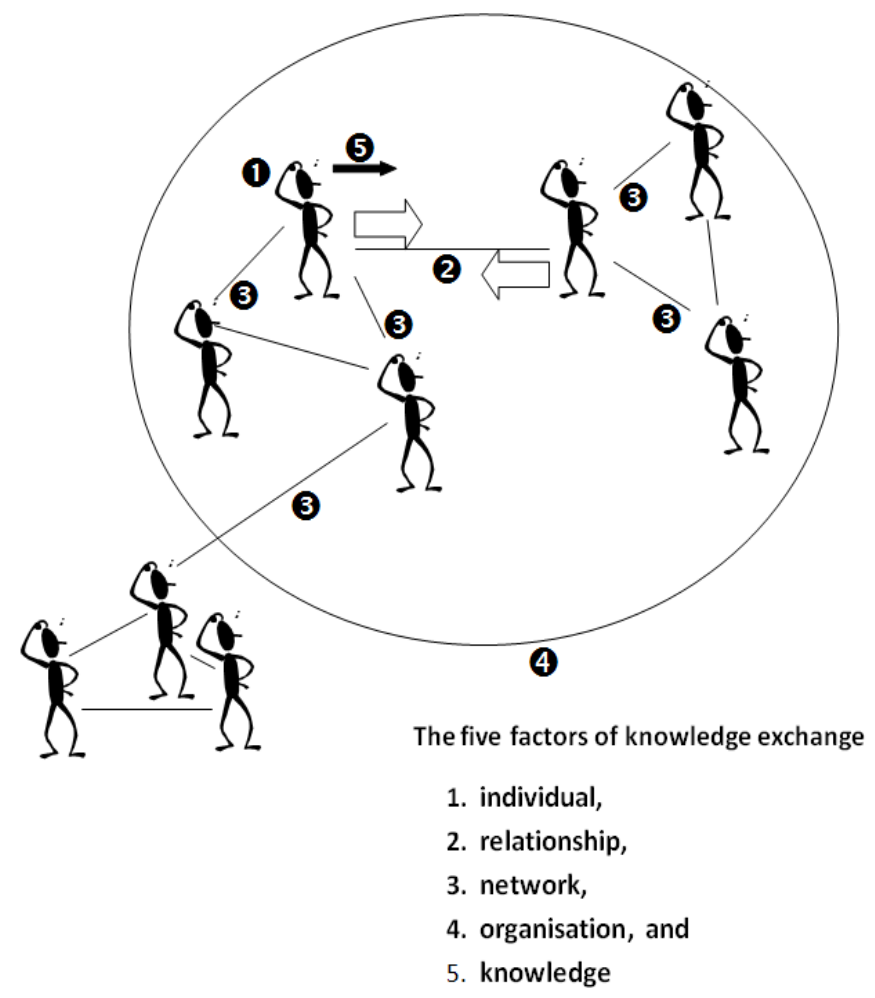

Figure 3. The five factors of knowledge exchange (Alony et al., 2007) 
At the same time, all of the memos which we had written through processes of abstraction and reflection, along with the major categories that had emerged, were printed out. We then cut them up and scattered them on the floor. These were compared and assessed to ensure that our theoretical development was in tune with the data and that there were no areas where our interpretation of categories could not easily be traced back to the data. This exercise of physically printing the memos and categories and arranging them on the floor was very helpful in ensuring that categories linked together meaningfully.

\section{Basic social process and theoretical model}

The final result of research using Grounded Theory as a method of qualitative analysis is a model depicting the basic social process. A basic social process is a core category that has been developed through densification and is found to substantially represent a major social process of the phenomenon under study. It is through the articulation and explanation of this basic social process that the explanatory theory emerges. To qualify as a basic social process the category must have "two or more clear emergent stages" (Glaser, 1978, p. 97). Basic social processes also share other important characteristics. They should be pervasive, in that they reflect and summarize the patterns of behavior which are fundamental to the phenomena, taking into account the moderating variables which work to alter the process. By being separate from a unit based structure basic social processes should be fully variable and therefore maintain validity in other settings and structures independent of social unit. Basic social processes are not only durable and stable over time; they are also flexible enough to accommodate for temporal change - or change over time - maintaining an interchangeable consistency in meaning, fit, and workability through the addition of new conditions and stages which account for the changing environment (Glaser, 1978). A basic social process focuses only on those variables that are related to the core category and those which are necessary in "relation to resolving the problematic nature of the pattern of behavior to be accounted for" (Glaser, 1978, p. 93).

It is possible that more than one core category will emerge from the research. If this is the case the researcher selects one of the core categories to develop into a basic social process and subsequent theory. Selection, in this case, is usually based on the core category which represents the main concern of the participants. The remaining core categories are not developed further, but can be reinstated in future studies.

Thus, the basic social process is the discovery of a human process that transcends the typical research boundary of 'social unit' by examining the social process occurring within that unit. Subsequently, studies revealing basic social processes are not grounded by their research context but gain a degree of universality (Glaser, 1978).

The basic social process identified in our study is the process of successful collaboration and knowledge exchange. We found individual motivation to be the main enabler of this success, dominating the influence of all other factors identified.

Another outcome is a collection of clearly articulated and conceptualized categories which, once sorted and integrated with relevant literature, become substantial components in the writing up of the research.

\section{Conclusion}

This paper demonstrates the contribution Grounded Theory has to offer to IS research and aims to provide annotated guidelines for using Grounded Theory in IS research. The paper explains the potential value Grounded Theory has to offer, the major criticism it has received in the field of IS, and an address of this criticism. The major focus of discussion is its provision of a detailed ac- 
count of the steps taken during IS research, the theoretical underpinning for these steps, and a demonstration of the findings resulting from each step.

In order to use Grounded Theory effectively, the researcher must adopt a non-traditional state of mind. Fernández and Lehmann (2005, p. 9) provided a list of seven principles - drawn from Glaser - to assist researchers in their adoption of Grounded Theory:

1. tolerate confusion - there is no need to know a priori and no need to force the data;

2. tolerate regression - the researcher might get briefly 'lost' before finding his or her way;

3. trust emerging data without worrying about justification - the data will provide the justification if the researcher adheres to the rigor of the method;

4. have someone to talk to-Grounded Theory demands moments of isolation to get deep in data analysis and moments of consultation and discussion;

5. be open to emerging evidence that may change the way the researcher thought about the subject matter, and to act on the new evidence;

6. be able conceptualize to derive theory from the data; and,

7. be creative - devising new ways of obtaining and handling data, combining the approach of others, or using a tested approach in a different way.

Grounded Theory appeals to researchers who can comply with these principles, in contrast to those who prefer a more structured, definitive, and, arguably, a more restricted approach. The inclusion of Grounded Theory research into the field of IS offers a broadening of the available points of view in the discipline, providing richer, and hopefully more authentic, accounts of reality.

\section{A Personal Reflection on Grounded Theory}

The selection of Grounded Theory in this study provided some advantages: Firstly, Grounded Theory allowed us to enter the field to discover the phenomena of greatest importance to the participants. We had been floundering around for some time, unable to conceive appropriate research questions which would allow the execution of more conventional research. Grounded Theory provided the opportunity to get on with the study. Secondly, Grounded Theory also made more sense. The progression of research is logical and practical. The researcher begins with only an idea of the area he or she intends to research, but as the research gains direction, focus and momentum, the researcher commences a gradual sensitization with extant literature (Suddaby, 2006, p.634). However, the literature does not inform the research, it is more a reality check for comparative purposes.

Thirdly, we liked the guiding structure that is provided by Grounded Theory. There was certain comfort in the analytical journey using its methods of coding and constant comparison because of its systematic and thorough construction. We also found the principle of theoretical sampling practical and useful. Other methods provide much less structure in this area. Finally, we felt that Grounded Theory offered the research a much more substantial end product. Most methods are designed to test theory, only a few actually build theory (Glaser \& Strauss, 1967). We wanted to build theory.

\section{References}

Ajmal, M. M., \& Koskinen, K. U. (2008). Knowledge transfer in project-based organizations: An organizational culture perspective. Project Management Journal, 39(1), 7-15.

Alony, I., Whymark, G., \& Jones, M. (2007). Sharing tacit knowledge: A case study in the Australian film industry. Informing Science: the International Journal of an Emerging Transdiscipline, 10, 41-59. Retrieved from http://www.inform.nu/Articles/Vol10/ISJv10p041-059Alony360.pdf 
Argote, L. (1999). Organizational learning: Creating, retaining, and transferring knowledge. Boston, Kluwer Academic.

Argote, L., \& Ingram, P. (2000). Knowledge transfer: A basis for competitive advantage in firms. Organizational Behavior and Human Decision Processes, 82(1), 150-169.

Backman, K., \& Kyngäs, H. A. (1999). Challenges of the grounded theory approach to a novice researcher. Nursing \& Health Sciences, 1(3), 147-153.

Baum, J., \& Ingram, P. (1998). Survival-enhancing learning in the Manhattan hotel industry, 1898-1980. Management Science, 44(7), 996-1016.

Bechky, B. A. (2000). Gaffers, gofers, and grips: Role-based coordination in temporary organizations. Organization Science, 17(1), 3-21.

Bechky, B. A. (2006). Talking about machines, thick description, and knowledge work. Organization Studies, 27(12), 1757.

Boh, W. F. (2007). Mechanisms for sharing knowledge in project-based organizations. Information and Organization, 17(1), 27-58.

Bryant, A. (2002). Re-grounding grounded theory. JITTA: Journal of Information Technology Theory and Application, 4(1), 25.

Burawoy, M. (1991). Reconstructing social theories. In M. Burawoy (Ed). Ethnography unbound. Power and resistance in the modern metropolis (pp. 8-27). Berkeley: University of California Press.

Cattani, G., \& Ferriani, S. (2008). A core/periphery perspective on individual creative performance: Social networks and cinematic achievements in the Hollywood film industry. Organization Science, 19(6), 824-844.

Charmaz, K. (1983). The grounded theory method: An explication and interpretation. In R. Emerson (Ed.), Contemporary field research: A collection of readings (pp. 109-126). Boston, MA: Little Brown Company.

Charmaz, K. (1990). 'Discovering' chronic illness: Using grounded theory. Social Science and Medicine, $30(11), 1161-1172$.

Charmaz, K. (2003). Grounded theory - Objectivist and constructivist methods. In N. K. Denzin \& Y. S. Lincoln (Eds.), Strategies of qualitative inquiry (pp. 249-291). London: Sage.

Charmaz, K. (2006). Constructing grounded theory: A practical guide through qualitative analysis. London: Sage Publications Ltd.

Charmaz, K. (2008). Grounded theory. In J. A. Smith (Ed.), Qualitative psychology: A practical guide to research methods (pp. 81-110). Los Angeles: SAGE.

Cooper, K. G., Lyneis, J. M., \& Bryant, B. J. (2002). Learning to learn, from past to future. International Journal of Project Management, 20(3), 213-219.

Daskalaki, M., \& Blair, H. (2002). Knowing as an activity: Implications for the film industry and semipermanent work groups. Proceedings of the Organisational Knowledge, Learning and Capabilities Conference. Athens 2002.

Davies, A., \& Brady, T. (2000). Organisational capabilities and learning in complex product systems: Towards repeatable solutions. Research Policy, 29(7-8), 931-953.

DeFillippi, R. J., \& Arthur, M. B. (1998). Paradox in project-based enterprise. California Management Review, 40(2), 125-139.

Denzin, N. K., \& Lincoln, Y. S. (2000). Introduction. In N. K. Denzin \& Y. S. Lincoln, The discipline and practice of qualitative research. Handbook of qualitative research (pp. 1-29). London: Sage.

Dey, I. (1999). Grounding grounded theory: Guidelines for qualitative inquiry. San Diego: Academic Press. 
Ellis, T. J., \& Levy, Y. (2009). Towards a guide for novice researchers on research methodology: Review and proposed methods. Issues in Informing Science and Information Technology, 6, 323-337. Retrieved from http://iisit.org/Vol6/IISITv6p323-337Ellis663.pdf

Fernández, W. D. (2004). The Glaserian approach and emerging business practices in information systems management: Achieving relevance through conceptualisation. 3rd European Conference on Research Methodology for Business and Management Studies. A. Brown and D. Remenyi. Reading UK, University of Reading.

Fernández, W. D., \& Lehmann, H. (2005). Achieving rigour and relevance in information systems studies: Using grounded theory to investigate organizational cases. The Grounded Theory Review, 5(1), 79107.

Fernández, W. D., Martin, M. A., Gregor, S. D., Stern, S. E., \& Vitale, M. R. (2006). A multi-paradigm approach to grounded theory. Information Systems Foundations Workshop: Constructing and Criticising, School of Accounting and Business Information Systems, College of Business and Economics, The Australian National University, Canberra, Australia, 2006.

Galal, G. H. (2001). From contexts to constructs: The use of grounded theory in operationalising contingent process models. European Journal of Information Systems, 10(1), 2.

Gee-Woo, B., Zmud, R. W., \& Sanjeev, S. (2005). Behavioral intention formation in knowledge sharing: Examining the roles of extrinsic motivators, social-psychological forces, and organizational climate. MIS Quarterly, 29(1), 87-111.

Geri, N., \& Geri, Y. (2011). The information age measurement paradox: Collecting too much data, Informing Science: the International Journal of an Emerging Transdiscipline, 14, 47-59. Retrieved from http://www.inform.nu/Articles/Vol14/ISJv14p047-059Geri587.pdf

Geertz, C. (1973). The interpretation of cultures: Selected essays. New York: Basic Books.

Giddens, A. (1984). The constitution of society: Outline of the theory of structuration. Berkely, CA: University of California Press.

Glaser, B. G. (1978). Theoretical sensitivity: Advances in the methodology of grounded theory. Mill Valley, CA: Sociology Press.

Glaser, B. G. (1992). Basics of grounded theory analysis. Mill Valley, CA: Sociology Press.

Glaser, B. G. (1998). Doing grounded theory. Issues and discussions. Mill Valley, CA: Sociology Press.

Glaser, B. G. (2001). The grounded theory perspective: Conceptualization contrasted with description. Mill Valley, CA: Sociology Press.

Glaser, B. G. (2005). The grounded theory perspective III: Theoretical coding. Mill Valley, CA: Sociology Press.

Glaser, B. G., \& Holton, J. (2004). Remodeling grounded theory: Article 4. Forum: Qualitative Social Research, 5(2), 1-17.

Glaser, B. G., \& Kaplan, W. D. (1996). Gerund grounded theory: The basic social process dissertation. Mill Valley, CA: Sociology Press.

Glaser, B. G., \& Strauss, A. (1967). The discovery of grounded theory: Strategies for qualitative research. New York: Aldine.

Goulding, C. (1998). Grounded theory: The missing methodology on the interpretivist agenda. Qualitative Market Research: An International Journal, 1(1), 50-57.

Goulding, C. (2001). Grounded theory: A magical formula or a potential nightmare. The Marketing Review, 2(1), 21-33.

Haas, M. R., \& Hansen, M. T. (2007). Different knowledge, different benefits: Toward a productivity perspective on knowledge sharing in organizations. Strategic Management Journal, 28(11), 1133-1153. 
Hettinga, M. (1998). Towards a theoretical foundation of EVOLVE: Report of an inventory of theories relevant for a conceptual model of evolving use of groupware. Telematica Instituut, 1-43.

Hobday, M. (2000). The project-based organisation: An ideal form for managing complex products and systems? Research Policy, 29(7-8), 871-893.

Hutchinson, S. A. (1988). Education and grounded theory. In R. R. Sherman \& R. B. Webb (Eds.), Qualitative research in education: Focus and methods. Lewes, UK: The Falmer Press.

Jones, M., \& Alony, I. (2007). Tacit knowledge, explicability and creativity - A case study of the Australian film industry. Working Papers in Design, 3, 1-17.

Jones, M. L., Kriflik, G., \& Zanko, M. (2005). Understanding worker motivation in the Australian film industry. Faculty of Commerce-Papers, 48.

Kankanhalli, A., Tan, C. Y., \& Wei, K. K. (2005). Contributing knowledge to electronic knowledge repositories: An empirical investigation. MIS Quarterly, 29(1), 113-143.

Ko, D. G., Kirsch, L. J., \& King, W. R. (2005). Antecedents of knowledge transfer from consultants to clients in enterprise system implementations. MIS Quarterly, 29(1), 59-85.

Landsberger, H. A. (1958). Hawthorne revisited: Management and the worker, its critics, and developments in human relations in industry. Ithaca, NY: Cornell University.

Lesser, E., \&Storck, J. (2001). Communities of practice and organizational performance. IBM Systems Journal, 40(4), 831-841.

Locke, K. (2001). Grounded theory in management research. London: Sage.

Martin, P. Y., \& Turner, B. A. (1986). Grounded theory and organizational research. The Journal of Applied Behavioral Science, 22(2), 141-157.

McLure-Wasko, M., \& Faraj, S. (2005). Why should I share? Examining social capital and knowledge contribution in electronic networks of practice. MIS Quarterly, 29(1), 35-57.

Mertens, D. M. (1998). Research methods in education and psychology. Thousand Oaks, CA: Sage.

Meyerson, D., Weick, K. E., \& Kramer, R. M. (1996). Swift trust and temporary groups. Trust in Organizations: Frontiers of Theory And Research, 166, 195.

Mintzberg, H., \& McHugh, A. (1985). Strategy formation in an adhocracy. Administrative Science Quarterly, 30(2), 160-197.

Nasirin, S., Birks, D. F., \& Jones, B. (2003). Re-examining fundamental GIS implementation constructs through the grounded theory approach. Telematics and Informatics, 20(4), 331-347.

Onions, P.E.W. (2006). Grounded theory application in reviewing knowledge management literature. Retrieved from http://www.lmu.ac.uk/research/postgradconf/papers/Patrick_Onions_paper.pdf

Orlikowski, W. J. (2002). Knowing in practice: Enacting a collective capability in distributed organizing." Organization Science, 13(3), 249-273.

Partington, D. (2000). Building grounded theories of management action. British Journal of Management, 11(2), 91.

Phillips, B. S. (1976). Social research: Strategy and tactics. New York: Macmillan.

Powell, W., Koput, K., \& Smith-Doerr, L. (1996). Interorganizational collaboration and the locus of innovation: Networks of learning in biotechnology. Administrative Science Quarterly, 41(1), 116-145.

Sarantakos, S. (2005). Social Research. Hampshire: Palgrave Macmillan.

Seldén, L. (2005). On Grounded Theory - with some malice. Journal of Documentation, 61(1), 114.

Skyrius, R., \& Bujauskas, V. (2010). A study on complex information needs in business activities. Informing Science: the International Journal of an Emerging Transdiscipline, 13, 1-13. Retrieved from http://www.inform.nu/Articles/Vol13/ISJv13p001-013Skyrius550.pdf 
Stern, P. N. (1994). Eroding grounded theory. In J. M. Morse (Ed.), Critical issues in qualitative research methods (pp. 212 -223). London: Sage.

Strauss, A., \& Corbin, J. (1990). Basics of qualitative research, grounded theory procedures and techniques. New York: Sage Publications.

Suddaby, R. (2006). From the editors: What grounded theory is not. Academy of Management Journal, 49(4), 633-642.

van Maanen, J. (1979a). The fact of fiction in organizational ethnography. Administrative Science Quarterly, 24(4), 539-550.

van Maanen, J. (1979b). Reclaiming qualitative methods for organizational research: A preface. Administrative Science Quarterly, 24(4), 520-526.

Walsham, G. (1995). Interpretive case studies in IS research: Nature and method. European Journal of Information Systems, 4(2), 74-81.

Walsham, G. (2006). Doing interpretive research. European Journal of Information Systems, 15(3), 320330 .

\section{Biographies}

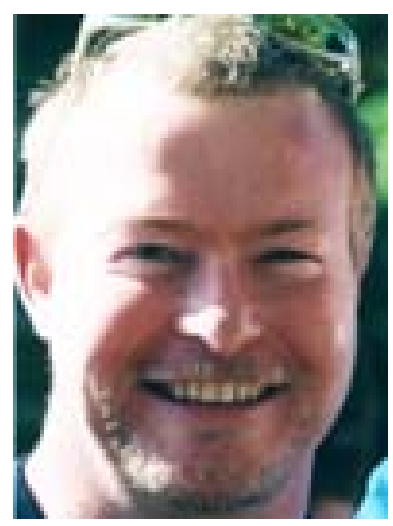

Michael Jones is a lecturer in Organizational Behavior in Australia's University of Wollongong. His recent writings focus on eCollaboration, especially with regard to small to medium enterprises, and on elements of Organizational Psychology. This work has led to a number of competitive grants for research. Early writings dealt with two principle areas; studies of qualitative methods, particularly in the field of grounded theory and computerized techniques for qualitative data analysis; and, organizational behavior, concentrating in areas of motivation and commitment. Michael received his Ph.D. in organizational behavior from the University of Wollongong.

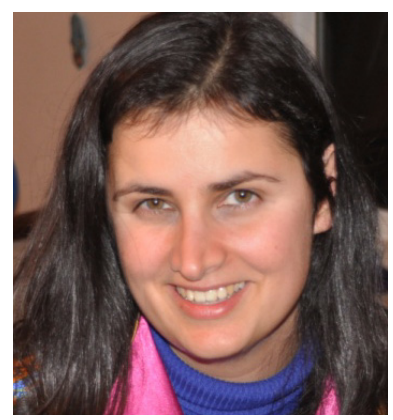

Irit Alony has been an academic teaching and researching in areas of information systems, management, and organisational behavior since 2006. Irit has developed research interests in the following areas: organisational culture, human decision making, affect and emotions in the workplace, and organisational psychology. Irit is also developing research strengths in areas of qualitative methods. Irit has recently started her Ph.D. on organisational turnover prediction in the University of Wollongong in Australia. 